\title{
Present self, past self and close-other: Event-related potential study of face and name detection
}

\author{
Ilona Kotlewska, Anna Nowicka* \\ Nencki Institute of Experimental Biology, Department of Neurophysiology, Laboratory of Psychophysiology, 3 Pasteur Street, 02-093 Warsaw, Poland
}

\section{A R T I C L E I N F O}

\section{Article history:}

Received 26 January 2015

Received in revised form 27 July 2015

Accepted 28 July 2015

Available online 30 July 2015

\section{Key words:}

Name

Face

P300

Present self

Past self

Close-other

\begin{abstract}
A B S T R A C T
A growing body of evidence suggests that information regarding the past self and other people is processed similarly. However, there is not much evidence supporting this notion at the neural level. In this event-related potential (ERP) study we examined processing of one's own marital and family name (i.e., present and past self-name, respectively) and images of present and past self-face in comparison to names and faces of others (the close-other, famous and unknown person). Amplitudes of P300 (a late ERP component associated with attention, emotion, and autobiographical memory) to self-face and selfname, either present or past, was enhanced in comparison to famous and unknown faces and names. No differences, however, were observed between the past and present self-names as well as between past and present self-faces. Moreover, P300 amplitude to the past self-face was enhanced in the right hemisphere in comparison to the close-other's face, whereas P300 amplitudes to the past self-name and the close-other's name did not differ. Thus, our results indicated that information related to non-physical aspects of the past self were processed similarly to the close-other.
\end{abstract}

(c) 2015 Elsevier B.V. All rights reserved.

\section{Introduction}

The sense of self-continuity seems to be an essential aspect of the human consciousness (Gallagher, 2000; Moran et al., 2006; Morin, 2006). It is related to autobiographical memory and it is based on the ability to consolidate different and temporally separated pieces of self-related information into a one coherent whole (Conway, 2005; McAdams, 2001). Life brings substantial changes (both physical, e.g., weight gain/loss and situational, e.g., start of a new job) as time passes, and these changes imply significant modifications of self-related information. As the self continually evolves, the self-concept is updated in order to account for these alterations (Demo, 1992; Deutsch et al., 1988).

A growing body of evidence indicates that people distance themselves from their past self when they perceive self-changes, even regarding their past self as ‘another person' (Libby \& Eibach, 2002; Pronin \& Ross, 2006; Wilson \& Ross, 2003). This is especially the case when recalling past behaviors and situations that are discrepant with the present self-concept. On such occasions people frequently adopt a third-person perspective, as if looking not at themselves

\footnotetext{
* Corresponding author. Fax: +48 228225342.

E-mail addresses: i.kotlewska@nencki.gov.pl (I. Kotlewska), a.nowicka@nencki.gov.pl (A. Nowicka).
}

but at someone else (Libby \& Eibach, 2002). Additionally, people asked to form images of past events in which they participated often claim to see them from the perspective of an external observer (e.g., Cohen \& Gunz, 2002). Also, attributions made about the past self resemble attributions made about others rather than attributions regarding the present self (Pronin \& Ross, 2006). All in all, it seems that following numerous personal changes people may process information about their past selves as information about others.

The topic of changes to the self across time has been the focus of many research groups. However, only a few attempts have been recently made to unravel the neural basis of temporally-distant selves. For both the present and distant time-periods, previous studies investigated self-reflection (D'Argembeau et al., 2008, 2010; Luo et al., 2010), subjective mental time (Arzy, Collette, Ionta, Fornari, \& Blanke, 2009), and self-face recognition (Apps, TajaduraJimenez, Turley, \& Tsakiris, 2012; Butler, Mattingley, Cunnington, \& Suddendorf, 2013).

In one of the earliest studies in this field, evaluations of psychological characteristics of one's own person and the other (friend) were conducted for both the present and a past time periods while functional magnetic resonance imaging (fMRI) data were collected (D'Argembeau et al., 2008). The degree of activity in cortical midline structures (CMS) was significantly influenced by both the target of reflection and period of time. The ventral and dorsal medial 
prefrontal cortex (MPFC) and the posterior cingulate cortex were more recruited when reflecting on the present self than when reflecting on the past self or when reflecting on the close friend, with those two conditions showing no differences. In a followup study, the MPFC activity was higher when reflecting on the present self than when reflecting on both past and future selves (D'Argembeau et al., 2010). The effects of temporal perspective, however, were not modulated by the trait valence.

Interestingly, this impact of emotional valence on the neural basis of self-evaluation across time was reported in an eventrelated potentials (ERP) study (Luo et al., 2010). In that study, for both present and past selves, the process of evaluation of negative traits in comparison to positive traits, resulted in higher amplitudes of a late positive ERP component (so-called late positive complex-LPC) in the $650-800 \mathrm{~ms}$ time window. The behavioral findings of this study indicated that for each temporal self, participants had consistently less negative and more positive views of themselves, in line with studies on self-enhancement (Leary, 2007; Sedikides \& Gregg, 2008).

Arzy et al. (2009), in turn, investigated subjective mental time, i.e., 'self-projection' of oneself to different time points not only with respect to one's life events but also with respect to one's faces from different past and future time-points. Participants were asked to imagine themselves at one of three different self-locations in time: 'now' (the present time), 'past' ( 8 years in the past) or 'future' ( 8 years in the future). Face images of the participant as well as a famous person (George Clooney) were modified in such a way that they represented the participant's and Clooney's face appearing as 4,12 and 20 years younger (past faces) or older (future faces). In one part of their experiment, faces of the participant or of Clooney were shown and participants were asked to indicate whether the presented face represented the participant's/Clooney's appearance before (relative-past) or after (relative-future) the imagined selflocation in time. Similarly, in the other part of the experiment participants were asked to indicate whether the presented event from their personal life or world history occurred before or after the currently imagined self-location in time. Analysis for past, present, and future self-locations revealed a network common for both faces and events, consisting of the right anteromedial temporal lobe, posterior parietal cortex bilaterally, left inferior frontal cortex, insula bilaterally, and right temporo-parietal junction. In a subset of these brain regions, the percent of fMRI signal change showed higher activation for the past and future self-locations than for the present self-location.

Finally, several studies reported changes in brain correlates associated with processing of present and past self-faces (Apps et al., 2012; Butler et al., 2013). Neural circuits involved in the recognition of childhood and current (adult) faces were examined using fMRI (Apps et al., 2012). Participants viewed images of either their own present face morphed with the face of a familiar other or their childhood face morphed with the childhood face of a familiar other. Morphed images of adult self-faces activated different neural networks than morphed images of self-faces in childhood. Specifically, activity in the inferior occipital gyrus, the superior parietal lobule and the inferior temporal gyrus varied with the amount of current self in an image whereas activity in the hippocampus, the posterior cingulate gyrus, the temporo-parietal junction and the inferior parietal lobule varied with the amount of childhood self in an image (Apps et al., 2012).

In a recent study, ERP responses to past and present images of participants' faces were investigated in a group of dizygotic twins (Butler et al., 2013). Photographs were taken when they were 5-15, 16-25 and 26-45 years old. The former two time periods referred to the past (more-distant and less-distant past, respectively) whereas the latter corresponded to the present, i.e., the period of time in which the experiments were done. Control stimuli consisted of the participant's twin and unfamiliar other's photographs of faces, coming from the same time periods. The results of this study clearly showed that amplitudes of N400 (a late negative ERP component in the 400-600 ms time window) differed as a function of time period, but only for images of self and not for twin. Processing of both the present self-face and the less-distant-past self-face resulted in greater $\mathrm{N} 400$ than identification of the self-face in the early period of life.

All in all, some of the aforementioned studies reported differences between neural underpinnings of the past and present selves (Arzy et al., 2009; D’Argembeau et al., 2008; D'Argembeau et al., 2010) whereas others did not (Luo et al., 2010). In two cases, such differences were found for the current self compared to the verydistant-past self, i.e., the self in childhood (Apps et al., 2012; Butler et al., 2013) but they were absent if the current self was compared to the less-distant-past self, i.e., the self in adolescence and early adulthood (Butler et al., 2013).

As far as relation between the past self and the other is concerned, not much evidence exists-at the neural level-supporting the notion that the past self is processed like the other. Only one study reported that neural circuits associated with evaluation of psychological traits in respect to the past self and the other (friend) did not differ (D'Argembeau et al., 2008). Other studies either did not include 'the other' as a control condition (D'Argembeau et al., 2010; Luo et al., 2010), or did not compare the past self vs. the other (Apps et al., 2012; Butler et al., 2013). Therefore, one may wonder whether the neural underpinnings associated with the past self and the close-other (friend, mother, etc.) are similar when processing of information other than personality traits is required.

For this reason, in the current study ERP responses to present and past self-faces and self-names were compared to ERP responses to faces and names of the close-other, famous, and unknown people. There is no doubt that one's own present and past faces are appropriate to capture time-related changes in the self (Butler et al., 2013). However, we propose that one's own name is also suitable to refer to the past and present selves if it has been changed at some point in life. Examples of such changes include protected witnesses and women who take their husband's name after marriage. It is worth noting that the latter is much more common than the former. Thus only married women who voluntarily changed their names participated in our study, and subject's family name was considered to be the past self-name, whereas the subject's marital name was the present self-name. In contrast to previous studies on past and present self-face processing that used a series of past selfface images (Arzy et al., 2009; Butler et al., 2013), only one image of the past self-face was presented to participants. It was taken just before the name-change (i.e., before marriage) and the image of the present self-face was taken just before participation in our study.

Similarly to our previous ERP studies on name and face processing, we used here written full names (Cygan, Tacikowski, Chojnicka, Ostaszewski, \& Nowicka, 2014; Tacikowski \& Nowicka, 2010; Tacikowski et al., 2011). Thus, these two different types of stimuli were presented within the same (visual) modality. This was done to reduce-as much as possible-the number of factors that could potentially differentiate ERPs to names and faces.

ERP studies within the framework of the person-recognition models (Bruce \& Young, 1986; Burton et al., 1990; Valentine, Moore, \& Brédart, 1995) identified several correlates of face and name processing. The occipito-temporal N170 (a negative deflection occurring around $170 \mathrm{~ms}$ after the stimulus onset) was shown to be sensitive to face inversion, but it was rather unaffected by the familiarity of a face (e.g., Bentin, Allison, Puce, Perez, \& McCarthy, 1996). $\mathrm{N} 170$ is often larger for names than for faces in the left hemisphere (Schweinberger, Ramsay, \& Kaufmann, 2006; Tacikowski et al., 2011) and larger for faces than for names in the right hemisphere (Rossion \& Jacques, 2008). Moreover, N170 is rather unaffected 
by the familiarity of names and faces (Eimer, 2000; Rossion et al., 2000; Schweinberger et al., 2004) and/or priming manipulations (Pfütze, Sommer, \& Schweinberger, 2002; Schweinberger, Kaufmann, Moratti, Keil, \& Burton, 2007; Schweinberger, Pickering, Burton, \& Kaufmann, 2002; Schweinberger, Pickering, Jentzsch, Burton, \& Kaufmann 2002). As a consequence, N170 is typically associated with stimulus-category discrimination. It is now widely agreed that N170 represents the analysis of structural information of faces (Bentin \& Deouell, 2000; Carbon et al., 2005; Eimer, 2000; Herzmann et al., 2004; Schweinberger, Pickering, Jentzsch et al., 2002) or word form analysis in case of names (Bentin, MouchetantRostaing, Giard, Echallier, \& Pernier, 1999).

Unlike N170, a subsequent temporal-parietal N250 (a relatively small negative deflection occurring around $250 \mathrm{~ms}$ after stimulus presentation) seems to reflect the activation of familiar face or familiar name representations stored in long-term memory (Schweinberger, Pickering, Jentzsch et al., 2002). N250 amplitude is: (1) larger for familiar than for unfamiliar names and faces (2) larger for perceptually primed than unprimed names and faces, and (3) unaffected by semantic priming (Sommer, Komoss, \& Schweinberger, 1997; Pfütze et al., 2002; Pickering \& Schweinberger, 2003; Schweinberger, Pickering, Jentzsch et al., 2002; Tacikowski et al., 2011). As a result, N250 was suggested to reflect the process of matching the input name or face to representations of names and faces stored in long-term memory (Miyakoshi, Nomura, \& Ohira, 2007).

Lastly, P300 (a positive component occurring around $300 \mathrm{~ms}$ after the stimulus onset, with its maximum over central-parietal scalp sites) has been related to multiple cognitive functions, including context updating, allocation of attentional resources and associative memory processes (for review see Polich, 2007). However, in the context of the person-recognition model P300 was associated mainly with access to semantic information about the person whose name or face is being recognized. Support for this claim comes from observations that P300 is modulated by the familiarity of names and faces and does not differentiate between names and faces (Bentin \& Deouell, 2000; Eimer, 2000; Paller et al., 2000; Schweinberger, 1996; Cygan et al., 2014; Tacikowski \& Nowicka, 2010; Tacikowski et al., 2011).

ERP studies prove strong modulation of brain activity by one's own name and face. The self-preference effect was found for ERP components described within the person recognition model-N170, N250, and P300 as well as for two additional components-P200 and N400. For some of those components such effect was present for both names and faces, whereas for others-for one type of stimulus only. The most consistent findings refer to P300. P300 amplitude is larger for one's own name than for other names (Berlad \& Pratt, 1995; Cygan et al., 2014; Fan et al., 2013; Folmer \& Yingling, 1997; Gray et al., 2004; Holeckova, Fischer, Giard, Delpuech, \& Morlet, 2006; Müller \& Kutas, 1996; Perrin et al., 2005; Scott et al., 2005; Sui, Zhu, \& Han, 2006; Tacikowski \& Nowicka, 2010; Tacikowski et al., 2011; Zhao et al., 2009). This effect seems to be task-independent since it was observed even during passive listening to the one's own name (Holeckova et al., 2008). Preferential responses to own name, as revealed by elevated P300, were present even in states of reduced consciousness, such as vegetative state or minimally conscious states (Di et al., 2007; Perrin et al., 2006; Staffen et al., 2006).

The processing of one's own face also resulted in much higher P300 amplitude than processing of other faces (e.g., Tacikowski \& Nowicka, 2010; Tacikowski et al., 2011; Tanaka et al., 2006) and, interestingly, this effect was not influenced by attentional manipulation and task-relevance, indicating an automatic process of self-face recognition (Cygan et al., 2014; Gunji et al., 2009; Sui et al., 2006). P300 is also significantly enhanced when processing of other types of self-related information, e.g., hometown, phone number, mother's first name, bank, birth date, initials etc. (Gray et al., 2004).

Apart from P300, different processing of self- vs. other names and self- vs. other faces was reported for N170. Höller et al. (2011) reported preferential processing when presenting one's own name aurally, reflected in higher amplitudes of N170. Analogous evidence for visual presentation of one's own name is missing, but similar early effects (at the level of N170) were found for selfface processing (Keyes, Brady, Reilly, \& Foxe, 2010). However, in the case of P200 (frontal-central component with approximate latency of $200 \mathrm{~ms}$ ) self-preferential effects were found for names only. $\mathrm{Hu}, \mathrm{Wu}$, and $\mathrm{Fu}(2011)$ reported that processing of semantic self-related information-participant's full name, date of birth, and hometown-was related to larger P200 responses than stranger's full name and self-irrelevant date and place. Fan et al., (2013) found that P200 was larger to the name of the participant than to the name of participant's father and to the names of famous people. Amplitudes of N250 component, in turn, were larger for both the self-name (Zhao et al., 2009) and for the self-face (Keyes et al., 2010; Tanaka et al., 2006) than to other names and faces, respectively. Self-face processing resulted also resulted in enhanced amplitudes of N400 in comparison to the face of twin (Butler et al., 2013) or a friend's face (Keyes et al., 2010), as well as in comparison to unfamiliar faces.

Previous studies showed that the processing of one's own name and/or images of one's own face is preferential and that this preference may occur at the early (N170, P200, N250) and late (P300, $\mathrm{N} 400$ ) stages of information processing. Based on our previous studies with presentation of names and faces (Cygan et al., 2014; Tacikowski \& Nowicka, 2010; Tacikowski et al., 2011; Tacikowski et al., 2014), we expected that in the current study effects related to the present and past selves as well as to the close other would emerge in P300. However, the other candidate was P200, although self-related effects for that component have so far involved one's own name only and were definitely not so often reported.

Preferential processing of self-related information has often been attributed to the highly arousing and attention-grabbing nature of self-related information (e.g., Hu et al., 2011). If this is the case, the self-preference effect should be observed even if any intentional discrimination between presented stimuli is not required, for instance in studies with a simple detection of stimuli. This supposition was supported by our previous study on name and face processing in which such a task was used with favorable results (Cygan et al., 2014). Specifically, detection of one's own name and one's own face resulted in increased amplitudes of P300 in comparison to all other names and faces (i.e., close-other's, famous, unknown). However, it is a matter of debate whether it is the case for self-related information referring to the past, i.e., whether automatic attention allocation may also be preferential for the past self-name and the past-self-face. Thus we decided to use a detection task in conjunction with ERP analysis.

Taking all of the aforementioned findings into account, the hypothesis referring to the present and past self-names and selffaces was based on: (i) Butler's et al., (2013) study, reporting a lack of significant ERP differences between the present self-face and past self-face from adolescence/adulthood; (ii) our previous ERP studies on name and face processing showing no differences between one's own (present) name and one's own (present) face (Cygan et al., 2014; Tacikowski \& Nowicka, 2010; Tacikowski et al., 2011). Thus we expected that Butler et al.'s findings would be 'extended' for present and past self-names.

As far as the relation between the past self and the close-other was concerned we hypothesized that it might be influenced by the type of information (names vs. faces). Based on D'Argembeau et al.'s study (2008) that reported lack of differences for 'psychological' ('non-physical') aspects of the past self and friend we expected 
similar neural underpinnings for the past self-name and the closeother's names as names are stimuli referring to the 'non-physical' aspects of a person. However, in the case of faces, reflecting physical aspects of past self and close-other, there were two alternative hypotheses: (i) the two conditions would result in similar ERP responses if any information related to the past self was processed like information related to the close-other; or (ii) past self-face and close-other face would be associated with different ERP responses if similarities between processing of information related to the pastself and the close-other were restricted only to the non-physical aspects of the past self and close-other.

\section{Methods}

\subsection{Participants}

Twenty five healthy female volunteers with normal or corrected-to-normal vision participated in the study. Only married women who accepted their spouse's last name were recruited. Three subjects were excluded from analyses due to excessive movement artifacts. Participants' ages varied from 24 to 60 (mean \pm standard deviation: $35.7 \pm 8.7$ ). The required minimal length of marriage was three years and varied from 3 to 37 $(9.64 \pm 8.86)$. None of the subjects had a history of neurological diseases. Handedness was controlled with the Edinburgh Inventory (Oldfield, 1971). Twenty three participants were right-handed, one left-handed, and one ambidextrous. Informed written consent was obtained from each participant prior to the study. All subjects were paid for their participation. The experimental protocol was approved by the local Ethics Committee (University of Social Sciences and Humanities, Warsaw, Poland).

\subsection{Stimuli}

Stimuli consisted of first and last names (which will still be referred to as 'names' for the sake of simplicity) and pictures of faces presented visually on a computer screen against a black background. Names were displayed with white letters and faces were rendered grayscale. Faces were extracted from their backgrounds using Adobe Photoshop CS5 ${ }^{\circledR}$ software (Adobe Systems Incorporated), rendering only the face, ears and hair visible. Picture luminance was matched to the color statistics of a single picture. The size of the stimuli ranged from $2 \times 3^{\circ}$ to $2 \times 6^{\circ}$ for names and from $5 \times 4^{\circ}$ to $5 \times 6^{\circ}$ for pictures. All pictures were resized to a height of 198 pixels.

Five different categories of stimuli were applied: (1) subject's marital name and face at present, (2) subject's family name and face in the past. As the control conditions name and face of (3) a close-other, (4) a famous person, e.g., a celebrity, and (5) an unknown person. Prior to the study participants were requested to deliver three photographs presenting: an actual image of selfface, an image of their face taken just before marriage, and a recent picture of a female close-other. One restriction was made on the choice of the close-other: first and last names (past or present) of the subject and the close-other had to differ in order to avoid associations of the latter with either past or present self-name. For this reason none of the subjects chose one's own mother, with most choosing their best friend, sister (two cases), or cousin (one case). The average length of acquaintance was $15 \pm 9.27$ years. Mean length of names (in number of letters) was as follows: present self-14.95 \pm 2.73 , past self- $15.5 \pm 3.54$, close-other $-13.86 \pm 2.25$, famous $-14.91 \pm 2.72$, and unknown $-14.93 \pm 2.69$. Name lengths did not differ significantly between categories (present vs. past $p>0.9$; present vs. close-other $p>0.9$; present vs. famous $p=0.88$; present vs. unknown $p>0.9$; past vs. close-other $p>0.9$; past vs. famous $p=0.60$; past vs. unknown $p>0.9$; close-other vs. famous $p>0.9$; close-other vs. unknown $p>0.9$; famous vs. unknown $p=0.16$ ). All of them were of Polish origin.

A set of stimuli was individually tailored for each subject. Famous and unknown persons were selected to match the length of first and last name, age and appearance of the subject. The photos of famous and unknown people were downloaded from the Internet. Prior to the experiment each participant confirmed familiarity with the famous person and denied acquaintance with the unknown one in her stimuli set.

\subsection{Experimental procedure}

Stimuli were displayed centrally on a 19-inch LCD monitor (NEC MultiSync 1990Fx). Stimuli presentation was designed using Presentation $^{\circledR}$ software (Neurobehavioral Systems, Albany, CA, USA). Participants were seated comfortably in an acoustically and electrically shielded room at a distance of $60 \mathrm{~cm}$ from the monitor. A simple detection task was applied: the participants responded to each stimulus as quickly as possible by pressing the same button on a Cedrus Response pad (RB-830, San Pedro, USA). The instructions were introduced twice: first verbally by the experimenter and then displayed on the monitor before the experiment started. Subjects had to confirm their understanding of the instruction by pressing the appropriate button.

Each trial consisted of the following sequence of events: presentation of a fixation cross (white "+" against black background) for $1000 \mathrm{~ms}$, the target item displayed for a maximum of $3000 \mathrm{~ms}$ unless the subject reacts earlier, and a blank screen for $1000 \mathrm{~ms}$. Responses caused disappearance of the target item. The sequence of stimuli presentation was pseudo-randomized so that no more than three stimuli of the same type or the same condition were presented consecutively. Stimulus of each type and category was presented 30 times. The experiment lasted approximately $15 \mathrm{~min}$.

After the experimental part of the task subjects were asked to fill out an Identification Form, which consisted of four questions regarding the subject's attitude to present and past name and face. The participants were asked to rate their level of identification with present/past name and present/past face on a 7-point scale where 1 corresponded to 'I do not identify myself with this name/photo' and 7 to 'I strongly identify myself with this name/photo'.

\subsection{EEG recordings}

EEG was continuously recorded from 62 scalp sites using a 128-channel amplifier (Quick Amp, Brain Products, Enschede, Netherlands) and BrainVisionRecorder ${ }^{\circledR}$ software (Brain Products, Gilching, Germany). Ag-AgCl electrodes were mounted on an elastic cap (ActiCAP, Munich, Germany) and positioned according to the extended 10-20 system. Electrode impedance was kept below $5 \mathrm{k} \Omega$. The EEG signal was recorded against an average of all channels calculated by the amplifier hardware. The sampling rate was $500 \mathrm{~Hz}$.

\subsection{Behavioral data analysis}

Responses within 200-2000 ms after the stimulus onset were scored as correct. Mean reaction times (RTs) were analysed using repeated measures ANOVA with 'type of stimuli' (two levels: names, faces) and 'condition' (five levels: present self, past self, close-other, famous, unknown) as within-subject factors. The Identification Form scale ratings were analysed using repeated measures ANOVA with two within-subject factors, each at two levels: 'type of stimuli' (names, faces) and 'time' (past, present). All effects with more than one degree of freedom in the numerator were adjusted for violations of sphericity (Greenhouse \& 
Identification with Present Face
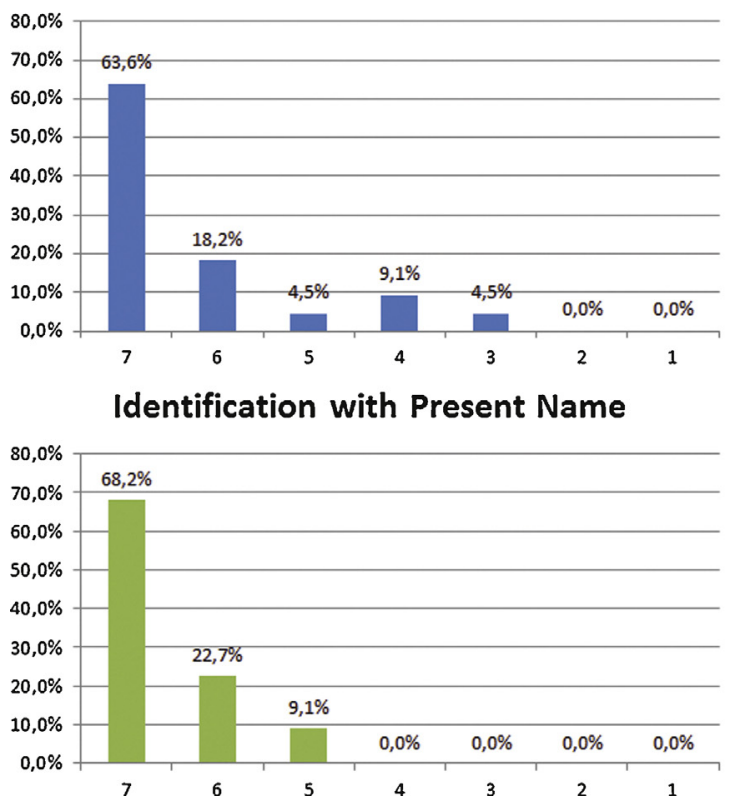

Identification with Past Face

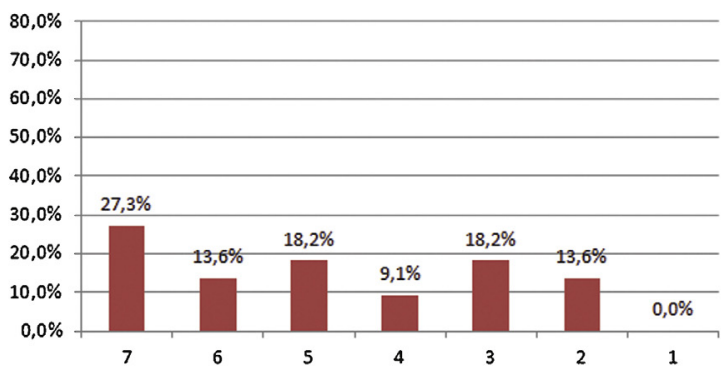

Identification with Past Name

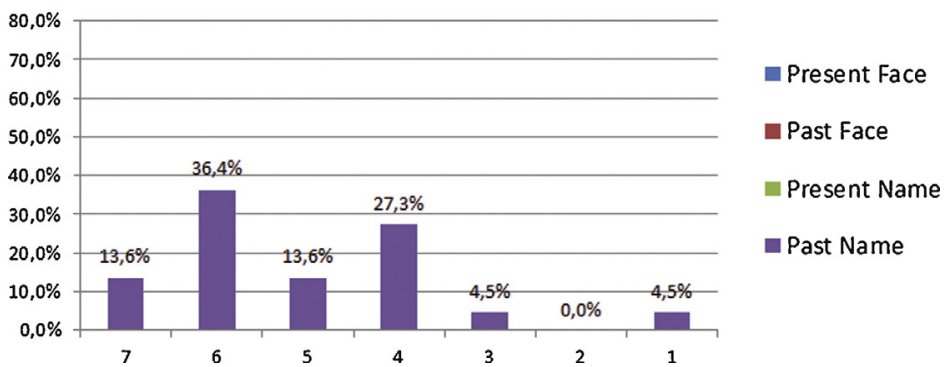

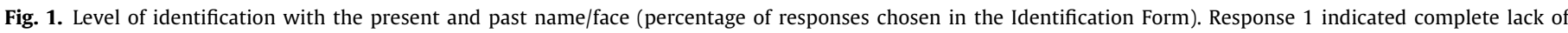

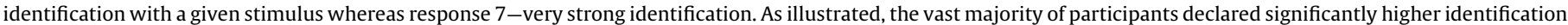
with their present face and name than the past ones.

Geisser, 1959). Bonferroni correction for multiple comparisons were applied to post-hoc analyses. All analyses were done in SPSS (Advanced Model).

\subsection{ERP analysis}

Off-line analysis of the EEG data was performed using BrainVisionAnalyzer ${ }^{\circledR}$ software (Brain Products, Gilching, Germany). The first step of analysis was to re-reference EEG data to the mean signal from earlobes. Subsequently, Butterworth Zero Phase filters were applied: low cutoff $-0.1 \mathrm{~Hz}, 12 \mathrm{~dB} /$ oct; high cutoff $-20 \mathrm{~Hz}, 12 \mathrm{~dB} / \mathrm{oct}$; and notch filter $-50 \mathrm{~Hz}$. Correction for ocular artifacts was performed with use of the Independent Components Analysis, ICA (Bell \& Sejnowski, 1995). After each data set was decomposed into maximally statistically independent components, the elements representing eye blinks were rejected based on a visual inspection of the component's map (Jung et al., 2001). The remaining components were multiplied using the reduced component-mixing matrix and back-projected to the data, resulting in a set of ocular-artifact-free EEG. Then the continuous EEG signal was segmented into epochs extending from $200 \mathrm{~ms}$ before to $1000 \mathrm{~ms}$ after the stimulus onset (baseline correction from -200 to $0 \mathrm{~ms}$ ). Next, the Analyzer's semi-automatic artifact rejection tool was used for rejecting trials exceeding the following terms: the maximum permitted voltage step per sampling point was $50 \mu \mathrm{V}$, the maximum permitted absolute difference between two values in the segment was $200 \mu \mathrm{V}$, and the lowest permitted activity in the $100 \mathrm{~ms}$ interval was $0.5 \mu \mathrm{V}$. Finally, the EEG segments were averaged for each category of stimuli to create ERP for a single subject.

Overall $98 \%$ of trials passed the artifact rejection procedure for both types of stimuli. The detailed range of accepted segments for each condition (for names and faces, respectively) was as follows: 98\% and $97 \%$ for present self, $98 \%$ and $98 \%$ for past self, $98 \%$ and $98 \%$ for close-other, $98 \%$ and $97 \%$ for famous, $98 \%$ and $97 \%$ for unknown.

The mean of values at each time point within a certain interval was used to assess amplitudes of our ERP components of interest. This method is less affected by possible low signal-to-noise ratio than the peak measures methods (Luck, 2005). Based on the visual inspection of grand-average ERPs and based on the existing literature, the following time-windows were used: $150-250 \mathrm{~ms}$ (P200) and 350-550 $\mathrm{ms}$ (P300).

We focused on scalp regions in which the above mentioned ERP components had their maximum amplitudes (see the topography maps in Figs. 2-4) and localizations reported in previous studies (e.g., Herzmann \& Sommer, 2007; Hu et al., 2011; Liu et al., 2013; Mu \& Han, 2010; Schweinberger et al., 2006; Tacikowski \& Nowicka, 2010; Tacikowski et al., 2011). P200 was analyzed in the frontalcentral region (F3, F4, FC3, FC4, FCz, Fz), and P300 in the centralparietal region (C3, C4, CP3, CP4, CPz, P3, P4, and Pz).

Amplitudes were analyzed using repeated measures ANOVA with 'type of stimuli' (two levels: names, faces), 'condition' (five levels: present self, past self, close-other, famous, unknown) and electrode site(P200-six levels: F3, F4, FC3, FC4, FCz, Fz; P300-eight levels: C3, C4, CP3, CP4, CPz, P3, P4, Pz) as within-subject factors. All effects with more than one degree of freedom in the numerator were adjusted for violations of sphericity (Greenhouse \& Geisser, 1959). Bonferroni correction for multiple comparisons were applied to post-hoc analyses. All analyses were done in SPSS (Advanced Model).

\section{Results}

\subsection{Behavioral results}

Statistical analysis of RTs did not show any significant effects. Mean RTs $( \pm S D)$ for each experimental condition were as follows: present name $-488 \pm 244 \mathrm{~ms}$, past name $-465 \pm 242 \mathrm{~ms}$, close-other's name $-461 \pm 219 \mathrm{~ms}$, famous name $-467 \pm 237 \mathrm{~ms}$, unknown name $-482 \pm 251 \mathrm{~ms}$, present face $-492 \pm 292 \mathrm{~ms}$, past face $-495 \pm 295 \mathrm{~ms}$, close-other's face $-491 \pm 287 \mathrm{~ms}$, famous face $-475 \pm 245 \mathrm{~ms}$, and unknown face $-486 \pm 260 \mathrm{~ms}$.

ANOVA carried on responses from the Identification Form revealed a main effect of time factor $(F(1,21)=26.72, p<0.001$, $\eta_{\mathrm{p}}{ }^{2}=0.56$ ), indicating a significantly higher level of identification with stimuli referring to the present self (present 

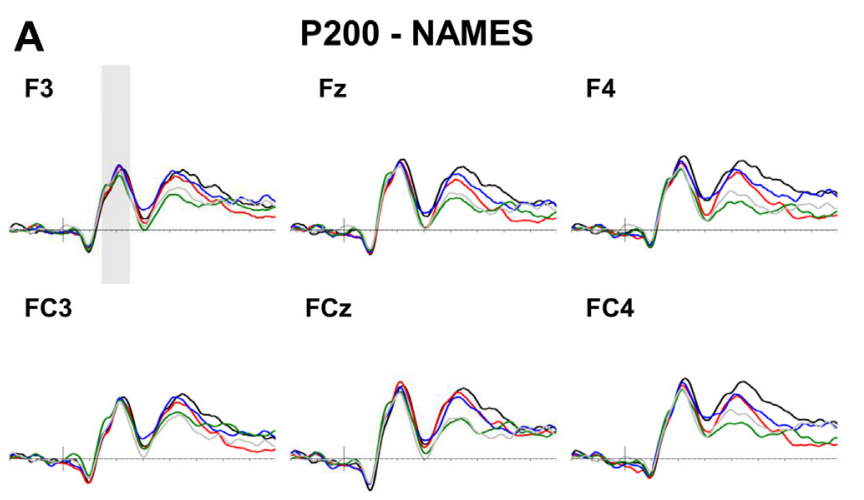

B
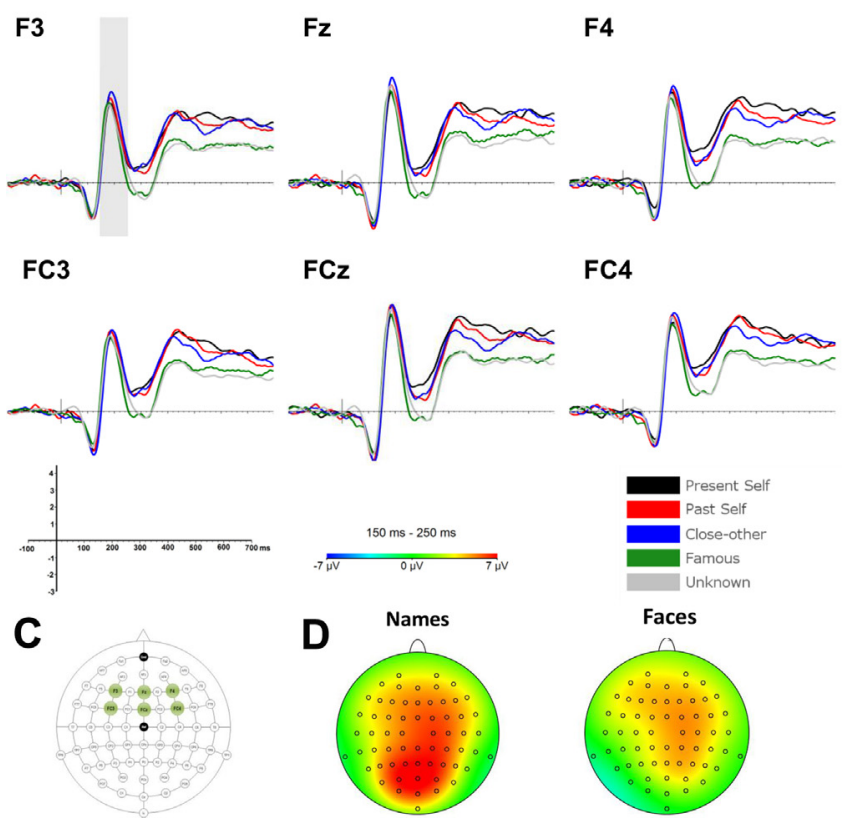

Fig. 2. Grand average ERPs for names (A) and faces (B). Green circles indicate electrode locations (F3, FC3, Fz, FCz, F4, FC4) at which mean amplitudes of P200 were analyzed (C). Topographic maps of the voltage in the analyzed time period, separately for names and faces (D).

name $-6.59 \pm 0.67$; present face-6.27 \pm 1.2 ) than with stimuli referring to the past self (past name-5.09 \pm 1.48 ; past face-4.82 \pm 1.84 ). Type of stimuli factor and its interaction with time factor were insignificant (see Fig. 1).

Pearson's correlation coefficients did not show significant correlations between the responses given in the Identification Form and the participants' age or length of marriage: identification with current self-name $x$ age, $r=0.136, p=0.546$; identification with current self-name $x$ wedlock, $r=0.07, p=0.755$; identification with past self-name $x$ age, $r=-0.133, p=0.557$; identification with past selfname $x$ wedlock, $r=-0.227, p=0.310$; identification with present self-face $x$ age, $r=0.185, p=0.410$; identification with present selfface $x$ wedlock, $r=0.184, p=0.412$; identification with past self-face $x$ age, $r=-0.191, p=0.394$, identification with past self-face $x$ wedlock, $r=-0.378, p=0.078$.

\subsection{Electrophysiological results}

\subsection{1. $P 200$}

ANOVA on P200 amplitudes revealed a significant main effect of electrode site $\left(F(2,50)=8.64, p<0.001, \eta_{\mathrm{p}}{ }^{2}=0.29\right)$. P200 amplitudes at electrode sites located in the midline were higher than
P200 amplitudes in the left hemisphere (Fz vs. F3, $p=0.002$; Fz vs $\mathrm{FC} 3, p=0.019$; FCz vs. F3, $p=0.004 ; \mathrm{FCz}$ vs. FC3, $p=0.004)$. The interaction: type of stimuli $x$ electrode site also reached the level of statistical significance $\left(F(3,63)=2.90, p<0.042, \eta_{\mathrm{p}}{ }^{2}=0.12\right)$. Posthoc tests showed that P200 to names was enhanced only at Fz in comparison to F3 ( $p=0.047)$ whereas P200 to faces was increased at electrode sites in the midline (Fz vs. F3, $p=0.001$; Fz vs. FC3, $p=0.022 ; \mathrm{FCz}$ vs. F3, $p=0.001$ ) and in the right hemisphere (FC4 vs. $\mathrm{F} 3, p=0.037$ ). All other effects and interactions were insignificant. Fig. 2 illustrates those results.

\subsection{2. $P 300$}

ANOVA on P300 amplitudes revealed a significant main effect of type of stimulus $\left(F(1,21)=18.23, p<0.001, \eta_{p}^{2}=0.46\right)$. In general, all faces elicited higher amplitudes than names (see Figs. 3 and 4 ). There was also a main effect of electrode site $(F(3,60)=6.57$, $\left.p<0.001, \eta_{\mathrm{p}}{ }^{2}=0.24\right)$ which was associated with significantly higher P300 amplitudes in the midline than in the left hemisphere $(\mathrm{Pz}>\mathrm{C} 3, p=0.008 ; \mathrm{Pz}>\mathrm{CP} 3, p=0.023 ; \mathrm{CPz}>\mathrm{C} 3, p=0.001 ; \mathrm{CP} 4>\mathrm{C} 3$, $p=0.048)$. In addition, post-hocs to a significant two-way interaction between type of stimuli and electrode site $(F(3,62)=13.67$, $p<0.001, \eta_{\mathrm{p}}{ }^{2}=0.39$ ) indicated that differences in $\mathrm{P} 300$ amplitudes between electrode sites were insignificant in the case of names (all $p s>0.2$ ) but they were significant in the case of faces $(\mathrm{C} 3<\mathrm{CPz}$, $p=0.001 ; \mathrm{C} 3<\mathrm{Pz}, p=0.001 ; \mathrm{C} 3<\mathrm{CP} 3, p=0.002 ; \mathrm{C} 3<\mathrm{CP} 4, p=0.015$; $\mathrm{C} 3<\mathrm{P} 3, p=0.001 ; \mathrm{C} 3<\mathrm{P} 4, p=0.017 ; \mathrm{CP} 3<\mathrm{Pz}, p=0.001 ; \mathrm{C} 4<\mathrm{Pz}$, $p=0.026 ; \mathrm{CP} 3<\mathrm{Pz}, p=0.001 ; \mathrm{CP} 3<\mathrm{P} 3, p=0.004)$.

Taking into account the goals of our study, the main points of interest were the condition factor (i.e., present self, past self, close-other, famous, unknown) and its interactions. ANOVA yielded a significant condition factor $(F(3,55)=13.63, p<0.001$, $\eta_{\mathrm{p}}{ }^{2}=0.39$ ). Post-hoc comparisons showed that $\mathrm{P} 300$ amplitudes in the present self condition (i.e., the present self-name, the present self-face) were significantly higher than P300 amplitudes in the close-other $(p=0.009)$, famous $(p=0.001)$ and unknown $(p=0.004)$ conditions (i.e., close-other's, famous and unknown names/faces). However, the present and past conditions (i.e., present and past self-name/self-face) were associated with similar P300 amplitudes $(p>0.9)$. The past self condition, in turn, resulted in enhanced P300 in comparison to the famous $(p=0.004)$ and unknown $(p=0.002)$ conditions. The difference between the past self and the close-other condition did not reach the level of statistical significance $(p=0.06)$.

Importantly, the significant interaction between condition, type of stimuli and electrode $\left(F(28,588)=1.69, p=0.016, \eta_{\mathrm{p}}^{2}=0.07\right)$, indicated that the effects found for some conditions differed in respect of the type of stimuli (names vs. faces) and/or location of electrode. Post-hoc comparisons showed no differences between P300 amplitude to the present self-name and past self-name at either of the analysed electrode sites ( $\mathrm{CPz}, \mathrm{Pz}, \mathrm{C} 3, \mathrm{C} 4, \mathrm{CP} 3, \mathrm{CP} 4$, $\mathrm{P} 3$, all $p s>0.9$; $\mathrm{P} 4, p=0.823$ ). Similarly, no differences were found between $\mathrm{P} 300$ amplitudes to the present self-face and past self-face at either of the analysed electrode sites ( $\mathrm{CPz}, \mathrm{Pz}, \mathrm{C} 3, \mathrm{C} 4, \mathrm{CP} 3, \mathrm{CP} 4$, P3, all ps >0.9; P4, $p=0.765$ ).

As far as the past self and the close-other's names and faces are concerned post-hoc test indicated that P300 amplitudes associated with the past self-name did not differ from the close-other's name at any electrode site (all ps >0.9). In the case of faces, however, difference between the past self-face and close-other's face was present in the right hemisphere at centro-parietal sites (CP4, $p=0.050 ; \mathrm{P} 4, p=0.053$ ). A similar weak trend was observed at the midline electrodes ( $\mathrm{CPz}, p=0.091 ; \mathrm{Pz}, p=0.088)$. No difference between $\mathrm{P} 300$ amplitudes to the past face and close-other's face was found at electrode sites in the left hemisphere (C3, $p>0.9 ; C P 3$, $p=0.378$; P3, $p=0.237$ ). 
A

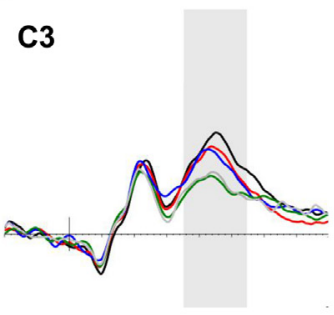

CP3

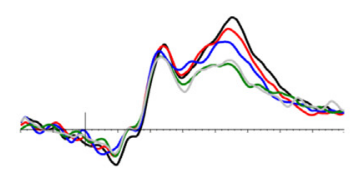

P3
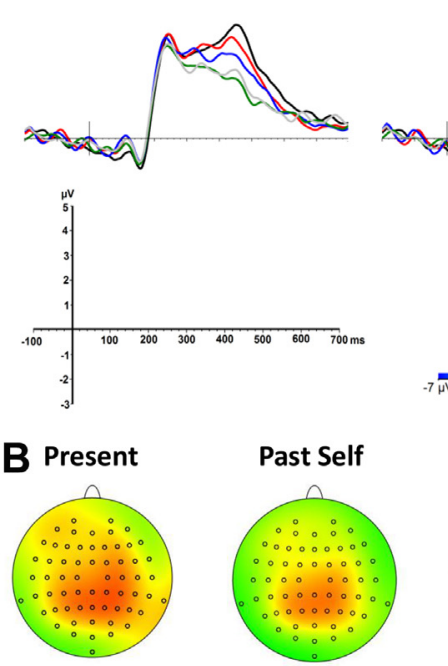

Pz

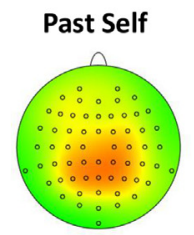

P300 - NAMES

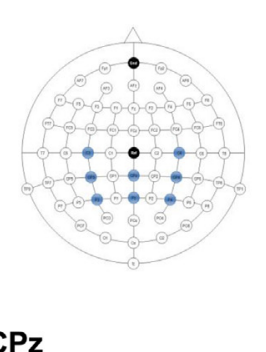

C4

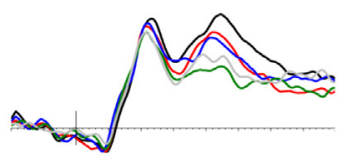

CP4
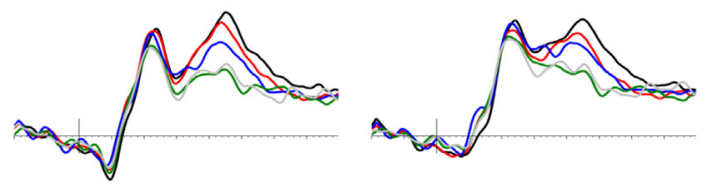

P4
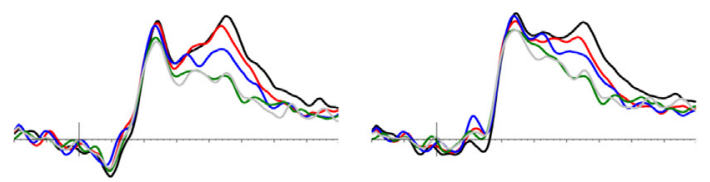
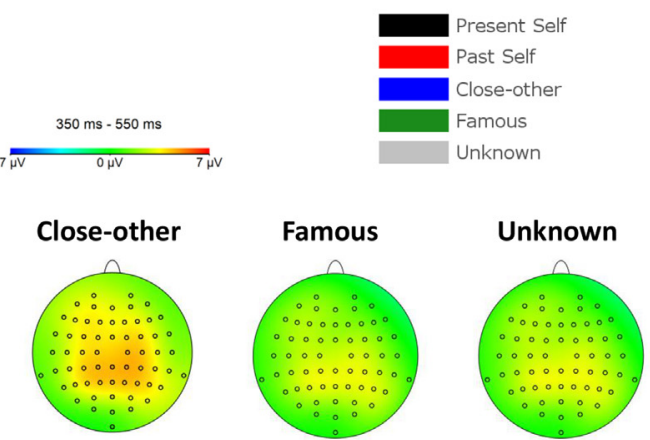

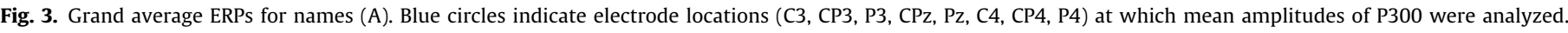

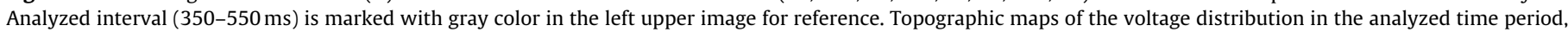
for each condition separately (B).

\section{Discussion}

One fundamental feature of the human conscious experience is a sense of self that persists across time. The design of our ERP study enabled us to shed further light on the neural processes that underpin processing of information related to the present self, the past self, and others. We hypothesized that processing of the present self-name/face and past self-name/face would not differ, resulting in similar ERP responses. In addition, we expected that relation between ERP responses to the past self and the close-other might be influenced by the type of information, i.e., whether it referred to physical (faces) or non-physical (names) aspects of person. Specifically, we hypothesized that the past self-name and the close-other's name would be similarly processed whereas it would rather not be the case for faces. Generally, results of our study supported those hypotheses.

Significant effects involving category of stimuli (i.e., whether they referred to present self, past self, close-other, famous person, unknown person) and type of stimuli (names vs. faces) were observed for P300. However, no effects were found for P200. In previous studies, enhanced P200 to self-related cues was reported in the case of evaluation of personality traits in relation to the self and others (Liu et al., 2013; Mu \& Han, 2010) or in the case of lying about the self and others (Hu et al., 2011). Moreover, P200 differences between the self-name vs. other names were found when overt recognition of names was required (Tacikowski et al., 2014) or when an oddball task was used (Fan et al., 2013). It seems that the absence of P200 effects in the current study may be a consequence of the substantial methodological differences. In some of the aforementioned studies rather complex cognitive processes were investigated (process of lying, reflecting on the self and the other, recognition of names). In addition, the allocation of attention might have been varying depending on the experimental procedure. For instance, in Fan et al.'s study names were used as an infrequent target stimuli among other words that had to be ignored. In contrast, in our study, the simple detection task did not require any intentional discrimination between presented stimuli, engaged attention automatically, and evoked the same motor reaction (i.e., pressing the same button) for each stimulus.

The results for P300 amplitudes showed that the present self condition (one's own present name, present self-face) was associated with higher amplitudes of P300 than famous, and unfamiliar 
A

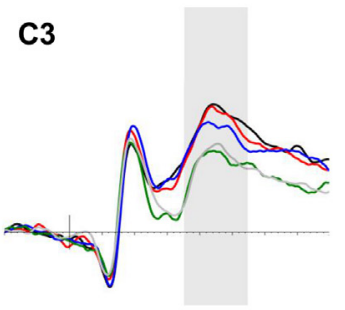

CP3

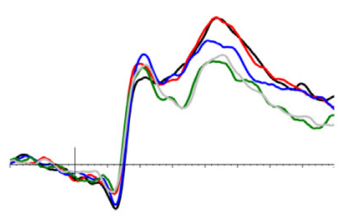

P3

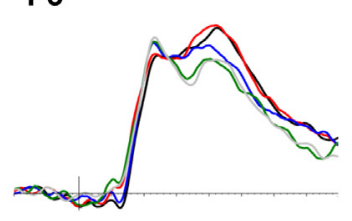

P300 - FACES

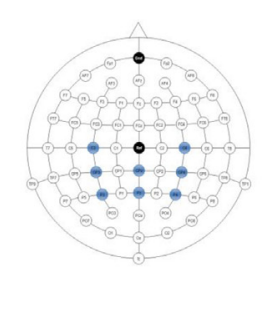

$\mathrm{CPz}$

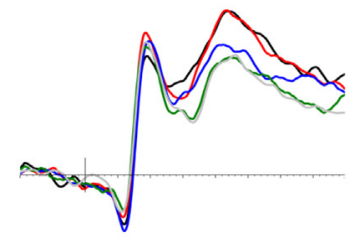

$\mathrm{Pz}$

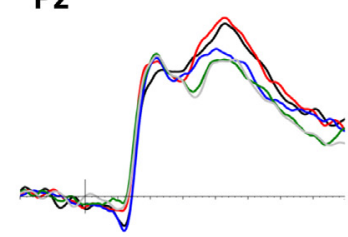

C4

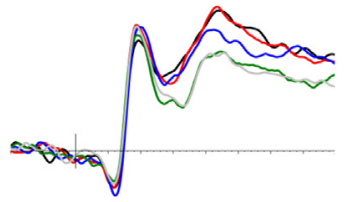

CP4

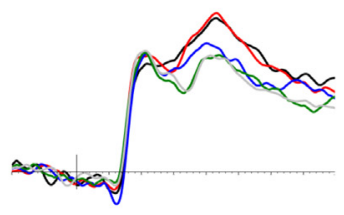

P4

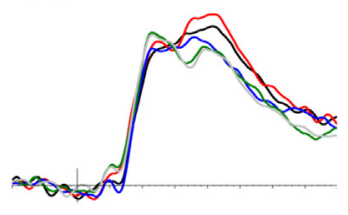

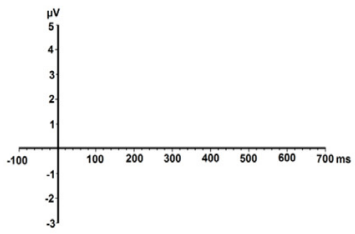
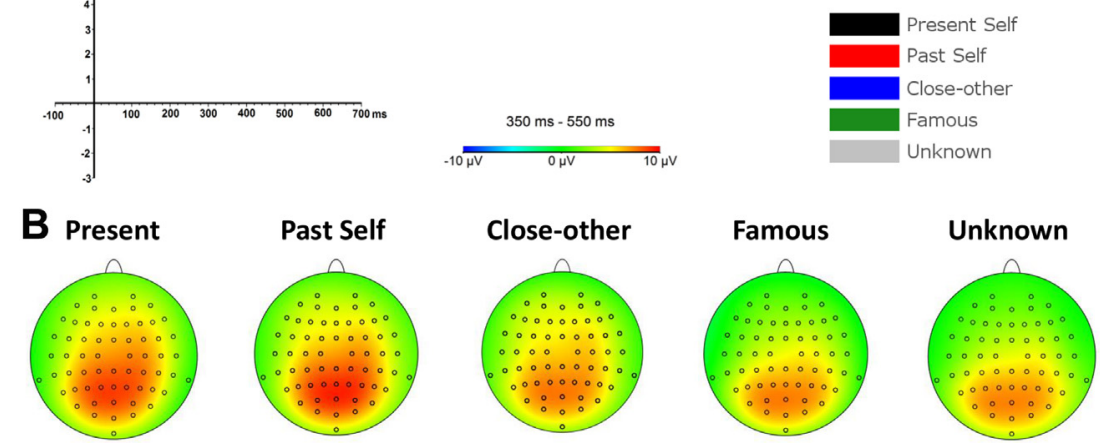

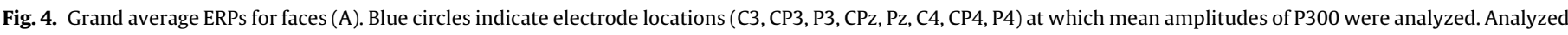

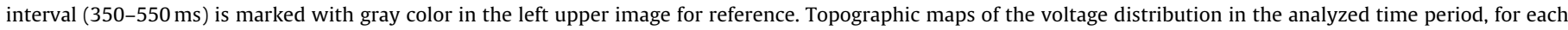
condition separately (B).

names and faces. These findings lay in line with numerous studies showing such a self-preference effect (Berlad \& Pratt, 1995; Cygan et al., 2014; Fan et al., 2013; Folmer \& Yingling, 1997; Gray et al., 2004; Holeckova et al., 2006; Müller \& Kutas, 1996; Perrin et al., 2005; Scott et al., 2005; Sui et al., 2006; Tacikowski \& Nowicka, 2010; Tacikowski et al., 2011; Tanaka et al., 2006; Zhao et al., 2009). P300 responses to the present self-name/face were also significantly increased in comparison to the close-other's name/face. The issue of similarities/dissimilarities between the neural correlates of (current) self and the close-other is a matter of ongoing debate and experimental evidence is rather inconclusive. For instance, no differences were found for names when recognition was required (Tacikowski et al., 2014). If stimuli related to the self were just detected (Cygan et al., 2014), neural differences between the self and the close-other were evident both for names and faces. Self-face identification, in turn, was also associated with higher amplitudes of late ERP responses (N400) than the twin-face identification but such effect was absent for earlier ERP components (Butler et al., 2013). In addition, reflection on psychological characteristics of the present self and the close-other engaged different neural circuits (D'Argembeau et al., 2008). This issue needs to be further investigated in order to find the factors that are crucial and critical for the emergence of differences between the present self and significant other at the neural level.

Importantly, we found no differences between P300 responses associated with processing of information related to the present self and past self, for either names or faces. Specifically, P300 to the present self-name did not differ from P300 to the past selfname, and a similar effect was observed for the present self-face and past self-face. Interestingly, although there was no difference on the neural level, behavioral results showed significantly higher levels of identification with stimuli referring to the present than the past self.

This pattern of P300 findings may be viewed in the context of person-recognition models (Bruce \& Young, 1986; Burton et al., 1990; Valentine et al., 1995). In these models, P300 is considered to reflect activation of semantic knowledge about the person being recognized (Herzmann \& Sommer, 2007; Kaufmann et al., 2008; Schweinberger, Pickering, Burton et al., 2002; Paller et al., 2000; Schweinberger et al., 2006; Tacikowski et al., 2011). Although in the current study conscious recognition of names and faces was not required and was not necessary to successfully accomplish the 
behavioral task (simple detection), it might have occurred when participants were viewing different names and faces. Thus, it cannot be excluded that similar P300 responses to the present and past self conditions were due to similar levels of semantic knowledge about the present and past selves. In addition, an attention-related interpretation of this effect may also be plausible because P300 has often been associated with attentional processes (for review see: Polich, 2007). In line with this, our P300 findings may show that present and past self-name as well as present and past-self faces engaged attentional resources to a similar extent.

In the context of the temporal perspective, the difference between the physical (face) and non-physical (name) aspects of the self is crucial. While the change of name happened once (at the time of marriage), changes in physical appearance are continuous due to the processes of aging and other factors. Thus information about the physical aspects of the self are constantly updated. Despite the punctual change for self-name and continuous changes for selfface, similar patterns of P300 findings were found for the present vs. past self-face and the present vs. past self-name. In addition, this difference could have influenced the behavioral results, and some decrease in identification with past name in comparison to past face might have been expected. However, levels of identification with the past self-name and past self-face did not differ. Moreover, the lack of P300 differences between the past self-name and the present self-name could be attributed to the fact that women who were married for many years may view their family (present) names as referring to both the present and the past selves. Although it is plausible, the vast majority of women participating in our study used their family names for a much longer time than their marital names (the average wedlock was 10 years, the average participant age was 36).

Previous studies reported that the temporal perspective exerted influence on neural correlates of self-face recognition only when the current (adult) self was compared to the "childhood self' (Apps et al., 2012; Butler et al., 2013). Such an effect, however, was absent when the current self was compared to the past, but not-so-distant, self (Butler et al., 2013). The latter perfectly corresponds to the lack of significant differences between the past and present self-faces in our study. In addition, the lack of differences between late positive ERP responses (LPC) to the present and past selves was observed in the case of psychological traits evaluation (Luo et al., 2010).

In contrast to the present self vs. the past-self comparisons that showed common effects for names and faces, the relation between the past self condition and the close-other condition was influenced by the type of stimuli. P300 to the past self-face was enhanced in comparison to the close-other's face in the right hemisphere whereas, P300 to the past self-name and P300 to the close-other's name did not differ. It is worth noting that observed neural differences between the past self-face and the close-other face have not been reported in previous studies on processing present and past self- and other faces (Apps et al., 2012; Butler et al., 2013). Specifically, analyses in Apps et al.'s study were focused on testing whether activity in any area of the brain scaled parametrically with the amount of one's own face in morphed images of one's own current face and the current face of a personally familiar other, or of one's own childhood face and the childhood face of the same personally familiar other. Butler et al., in turn, investigated the influence of temporal perspective within a given identity (self, dizygotic twin, unfamiliar other) and not across identities for different time periods (e.g., past self vs. present other).

To the best of the authors' knowledge, only one previous study showed similar neural underpinnings of the past self and the close-other (friend) (D'Argembeau et al., 2008). In that study, the evaluation of psychological characteristics of one's own person in the past and the friend activated the ventral and dorsal (MPFC) and the posterior cingulate cortex to the same extent. Thus both
studies-D'Argembeau et al.'s (2008) and ours-provide converging evidence on similar neural responses to the non-physical aspects of the past self and the close-other despite methodological differences: the experimental task (reflection vs. detection), measures of brain activity (fMRI vs. ERP), and stimuli (personality traits vs. names).

One may speculate that similarly enhanced P300 responses to the past self-name and the close-other name may be attributed to the comparable emotional content of those stimuli. This supposition was based on the notion that P300 varies with the emotional value of the stimulus and that emotionally charged stimuli (regardless of their valence) produced larger P300 than neutral ones (Dietrich et al., 2001; Johnston et al., 1986). The pattern of P300 findings for the past self-name and the close-other name may be also related to the hypothesis about shared mental and neural representations of the past self and the significant other. Perceiving and appreciating the cognitive and emotional similarity between oneself and other people is an obligatory stage in the normal development of the self that is crucial for social interactions (Decety \& Sommerville, 2003; Gopnik \& Meltzoff, 1994). This development requires "forming and coordinating specific social representations of self and other $(. .$.$) that extract patterns of similarity between$ self and other" (Rogers \& Pennington, 1991). Self-other integration typically grows from the depth of shared experiences (Gopnik \& Meltzhoff, 1994; Slotter \& Gardner, 2009 Slotter \& Gardner, 2009). Such experiences are common especially if the 'other' is highly familiar and emotionally related to the subject (i.e., the case of the close-other in our study). Moreover, the cognitive significance of being in a close-relationship with other people is described in terms of including other into the concept of the self (Aron, Aron, Tudor, \& Nelson, 1991; Aron et al., 2004).

In addition, it could not be ruled out that the P300 results reported here were related to the frequency of occurrence. In everyday life, self-name and self-face, either past or present, as well as the close-other's name and were encountered much more often than famous and unknown names and faces. Although previous studies showed that the P300 component is modulated more by the semantic than by the perceptual-familiarity factor (Bentin \& Deouell, 2000; Eimer, 2000; Paller et al., 2000; Schweinberger, 1996; Tacikowski et al., 2011), the issue needs further investigation. For instance, Butler et al., (2013) proposed the exposure factor as one of the major agents influencing the neural processing of the self-face vs. others' faces. This may be valid for faces of own and other race, i.e., the own-race bias (Meissner \& Brigham, 2001) and even for faces of own and other ages, i.e., the own-age bias (Hills \& Lewis, 2011). Following this idea, the duration of time that a person sees the given stimulus differentiates the face processing. Consequently, the daily exposure to own face across the lifespan shall be carefully addressed in the processes of the visual self- vs. other recognition.

In conclusion, the processing of information (names, faces) referring to the present self and the past self was associated with similar P300 responses. However, P300 to the past self-face was enhanced in comparison to P300 to the close-other's face. This may indicate that physical aspects of the past self are differentiated from the close-other. In contrast, no difference between P300 responses to the past self-name and the close-other's name suggests that nonphysical aspects of the past self and to the close-other are processed similarly.

\section{Acknowledgments}

This work was funded by the Polish National Science Centre [grant 2012/07/B/HS6/01283]. Funding sources had no involvement in study design, in data collection, analysis and interpretation, 
in the writing of the report, and in the decision to submit the manuscript for publication.

\section{References}

Apps, M., Tajadura-Jimenez, A., Turley, G., \& Tsakiris, M. (2012). The different faces of one's self: an fMRI study into the recognition of current and past self-facial appearances. Neuroimage, 63, 1720-1729. http://dx.doi.org/10.1016/j. neuroimage.2012.08.053

Aron, A., Aron, E. N., Tudor, M., \& Nelson, G. (1991). Close-relationships as including other in the self. Journal of Personality and Social Psychology, 60, 241-253. http://dx.doi.org/10.1037/0022-3514.60.2.241

Aron, A., Mclaughlin-Volpe, T., Mashek, D., Lewandowski, G., Wright, S. C., \& Aron, E. N. (2004). Including others in the self. European Review of Social Psychology, 15, 101-132. http://dx.doi.org/10.1080/10463280440000008

Arzy, S., Collette, S., Ionta, S., Fornari, E., \& Blanke, O. (2009). Subjective mental time: the functional architecture of projecting the self to past and future. European Journal of Neuroscience, 30, 2009-2017. http://dx.doi.org/10.1111/j. 1460-9568.2009.06974.x

Bell, A. J., \& Sejnowski, T. J. (1995). An information-maximization approach to blind separation and blind deconvolution. Neural Computation, 7, 1129-1159. http://dx.doi.org/10.1162/neco.1995.7.6.1129

Bentin, S., Allison, T., Puce, A., Perez, E., \& McCarthy, G. (1996). Electrophysiological studies of face perception in humans. Journal of Cognitive Neuroscience, 8 , 551-565. http://dx.doi.org/10.1162/jocn.1996.8.6.551

Bentin, S., \& Deouell, L. Y. (2000). Structural encoding and identification in face processing; ERP evidence for separate mechanisms. Cognitive Neuropsychology, 17, 35-54. http://dx.doi.org/10.1080/026432900380472

Bentin, S., Mouchetant-Rostaing, Y., Giard, M. H., Echallier, J. F., \& Pernier, J. (1999). ERP manifestations of processing printed words at different psycholinguistic levels: time course and scalp distribution. Journal of Cognitive Neuroscience, 11, 235-260. http://dx.doi.org/10.1162/089892999563373

Berlad, I., \& Pratt, H. (1995). P300 in response to subject's own name. Electroencephalography and Clinical Neurophysiology, 96, 472-474. http://dx. doi.org/10.1016/0168-5597(95)00116-A

Bruce, V., \& Young, A. (1986). Understanding face recognition. British Journal of Psychology, 77, 305-327. http://dx.doi.org/10.1111/j.2044-8295.1986.tb02199.

$\mathrm{X}$
Burton, A. M., Bruce, V., \& Johnson, R. A. (1990). Understanding face recognition with an interactive activation model. British Journal of Psychology, 81, 361-380. http://dx.doi.org/10.1111/j.2044-8295.1990.tb02367.x

Butler, D. L., Mattingley, J. B., Cunnington, R., \& Suddendorf, T. (2013). Different neural processes accompany self-recognition in photographs across the lifespan: an ERP study using dizygotic twins. PloS One, 8, e72586. http://dx.doi. org/10.1371/journal.pone.0072586

Carbon, C. C., Schweinberger, S. R., Kaufmann, J. M., \& Leder, H. (2005). The Thatcher illusion seen by the brain: an event-related brain potentials study. Cognitive Brain Research, 24, 544-555. http://dx.doi.org/10.1016/j.cogbrainres. 2005.03.008

Cohen, D. C., \& Gunz, A. (2002). As seen by the other. ..: perspectives on the self in the memories and emotional perceptions of Easterners and Westerners. Psychological Science, 13, 55-59. http://dx.doi.org/10.1111/1467-9280.00409

Conway, M. (2005). Memory and the self. Journal of Memory and Language, 53, 594-628. http://dx.doi.org/10.1016/j.jml.2005.08.005

Cygan, H., Tacikowski, P., Chojnicka, I., Ostaszewski, P., \& Nowicka, A. (2014). Neural correlates of own name and own face detection in Autism Spectrum Disroder: ERP study. PloS One, 9, 86020. http://dx.doi.org/10.1371/journal.pone.0086020

D'Argembeau, A., Feyers, D., Majerus, S., Collette, F., Van der Linden, M., Maquet, P., et al. (2008). Self-reflection across time: cortical midline structures differentiate between present and past selves. Social Cognitive and Affective Neuroscience, 3, 244-252. http://dx.doi.org/10.1093/scan/nsn020

D’Argembeau, A., Stawarczyk, D., Majerus, S., Collette, F., Van der Linden, M., Feyers, D., et al. (2010). The neural basis of personal goal processing when envisioning future events. Journal of Cognitive Neuroscience, 22, 1701-1713. http://dx.doi.org/10.1162/jocn.2009.21314

Decety, J., \& Sommerville, J. A. (2003). Shared representations between self and other: a social cognitive neuroscience view. Trends in Cognitive Sciences, 7 , 527-533. http://dx.doi.org/10.1016/j.tics.2003.10.004

Demo, D. (1992). The self-concept over time: research issues and directions. Annual Review of Sociology, 18, 303-326. http://dx.doi.org/10.1146/annurev.so. 18.080192.001511

Deutsch, F. M., Ruble, D. N., Fleming, A., Brooks-Gunn, J., \& Stangor, C. (1988). Information-seeking and maternal self-definition during the transition to motherhood. Journal of Personality and Social Psychology, 55, 420-431. http:// dx.doi.org/10.1037/0022-3514.55.3.420

Di, H. B., Yu, S. M., Weng, X. C., Laureys, S., Yu, D., Li, J. Q., et al. (2007). Cerebral response to patient's own name in the vegetative and minimally conscious states. Neurology, 68, 895-899. http://dx.doi.org/10.1212/01.wnl.0000258544. 79024.d0

Dietrich, D. E., Waller, C., Johannes, S., Wieringa, B. M., Emrich, H. M., \& Muente, T. F. (2001). Differential effects of emotional content on event-related potentials in word recognition memory. Neuropsychobiology, 43, 96-101. http://dx.doi. org/10.1159/000054874
Eimer, M. (2000). Event-related brain potentials distinguish processing stages involved in face perception and recognition. Clinical Neurophysiology, 111, 694-705. http://dx.doi.org/10.1016/S1388-2457(99)00285-0

Fan, W., Chen, J., Wang, X.-Y., Cai, R., Tan, Q., Chen, Y., et al. (2013). Electrophysiological correlation of the degree of self-reference effect. PloS One, 8, e80289. http://dx.doi.org/10.1371/journal.pone.0080289

Folmer, R. L., \& Yingling, C. D. (1997). Auditory P3 responses to name stimuli. Brain and Language, 56, 306-311. http://dx.doi.org/10.1006/brln.1997.1828

Gallagher, S. (2000). Philosophical conceptions of the self: implications for cognitive sciences. Trends in Cognitive Sciences, 4, 14-21. http://dx.doi.org/10. 1016/S1364-6613(99)01417-5

Gopnik, A., \& Meltzoff, A. N. (1994). Minds, bodies, and persons: Young children's understanding of the self and others as reflected in imitation and theory of mind research. In S. T. Parker, R. W. Mitchell, \& M. L. Boccia (Eds.), Self-awareness in animals and humans: developmental perspectives ( $\mathrm{pp}$. 166-186). Cambridge: Cambridge University Press.

Gray, H. M., Ambady, N., Lowenthal, W. T., \& Deldin, P. (2004). P300 as an index of attention to self-relevant stimuli. Journal of Experimental Social Psychology, 40, 216-224. http://dx.doi.org/10.1016/S0022-1031(03)00092-1

Greenhouse, S. W., \& Geisser, S. (1959). On methods in the analysis of profile data. Psychometrika, 24, 95-112. http://dx.doi.org/10.1007/BF02289823

Gunji, A., Inagaki, M., Inoue, Y., Takeshima, Y., \& Kaga, M. (2009). Event-related potentials of self-face recognition in children with pervasive developmental disorders. Brain and Development, 31, 139-147. http://dx.doi.org/10.1016/j. braindev.2008.04.011

Höller, Y., Kronbichler, M., Bergmann, J., Crone, J. S., Ladurner, G., \& Golaszewski, S. (2011). EEG frequency analysis of responses to the own-name stimulus. Clinica Neurophysiology, 122, 99-106. http://dx.doi.org/10.1016/j.clinph.2010.05.029

Herzmann, G., Schweinberger, S. R., Sommer, W., \& Jentzsch, I. (2004). What's special about personally familiar faces? A multimodal approach. Psychophysiology, 41, 688-701. http://dx.doi.org/10.1111/j.1469-8986.2004. 00196.x

Herzmann, G., \& Sommer, W. (2007). Memory-related ERP components for experimentally learned faces and names: characteristics and parallel-test reliabilities. Psychophysiology, 44, 262-276. http://dx.doi.org/10.1111/j.14698986.2007.00505.x

Hills, P., \& Lewis, M. (2011). The own-age face recognition bias in children and adults. The Quarterly Journal of Experimental Psychology, 64, 17-23. http://dx. doi.org/10.1080/17470218.2010.537926

Holeckova, I., Fischer, C., Giard, M. H., Delpuech, C., \& Morlet, D. (2006). Brain responses to subject's own name uttered by a familiar voice. Brain Research, 1082, 142-152. http://dx.doi.org/10.1016/j.brainres.2006.01.089

Holeckova, I., Fischer, C., Morlet, D., Delpuech, C., Costes, N., \& Mauguiere, F. (2008). Subject's own name as a novel in a MMN design: a combined ERP and PET study. Brain Research, 1189, 152-165. http://dx.doi.org/10.1016/j.brainres. 2007.10.091

Hu, X., Wu, H., \& Fu, G. (2011). Temporal course of executive control when lying about self-and other-referential information: an ERP study. Brain Research, 1369, 149-157. http://dx.doi.org/10.1016/j.brainres.2010.10.106

Johnston, V. S., Miller, D. R., \& Burleson, M. H. (1986). Multiple P3s to emotional stimuli and their theoretical significance. Psychophysiology, 23, 684-694. http://dx.doi.org/10.1111/j.1469-8986.1986.tb00694.x

Jung, T., Makeig, S., Westerfield, M., Townsend, J., Courchesne, E., \& Sejnowski, T. (2001). Analysis and visualization of single-trial event-related potentials. Human Brain Mapping, 14, 166-185. http://dx.doi.org/10.1002/hbm.1050

Kaufmann, J. M., Schweinberger, S. R., \& Burton, A. M. (2008). N250 ERP correlates of the acquisition of face representations across different images. Journal of Cognitive Neuroscience, 21, 625-641. http://dx.doi.org/10.1162/jocn.2009. 21080

Keyes, H., Brady, N., Reilly, R. B., \& Foxe, J. J. (2010). My face or yours? Event-related potential correlates of self-face processing. Brain and Cognition, 72, 244-254. http://dx.doi.org/10.1016/j.bandc.2009.09.006

Leary, M. R. (2007). Motivational and emotional aspects of the self. Annual Review of Psychology, 58, 317-344. http://dx.doi.org/10.1146/annurev.psych.58. 110405.085658

Libby, L. K., \& Eibach, R. P. (2002). Looking back in time: self-concept change affects visual perspective in autobiographical memory. Journal of Personality and Socia Psychology, 82, 167-179. http://dx.doi.org/10.1037/0022-3514.82.2.167

Liu, Y., Sheng, F., Woodcock, K. A., \& Han, S. (2013). Oxytocin effects on neural correlates of self-referential processing. Biological Psychology, 94, 380-387. http://dx.doi.org/10.1016/j.biopsycho.2013.08.003

Luck, S. J. (2005). Ten simple rules for designing ERP experiments. In T. C. Handy (Ed.), Event-related potentials. A methods handbook (pp. 209-227). Cambridge MA: The MIT Press.

Luo, Y., Huang, X., Chen, Y., Jackson, T., \& Wei, D. (2010). Negativity bias of the self across time: an event related potentials study. Neuroscience Letters, 475, 69-73. http://dx.doi.org/10.1016/j.neulet.2010.03.042

Müller, H. M., \& Kutas, M. (1996). What's in a name? Electrophysiological differences between spoken nouns, proper names and one's own name. Neuroreport, 8, 221-225. http://dx.doi.org/10.1097/00001756-19961220000045

McAdams, D. (2001). The psychology of the life stories. Review of General Psychology, 5, 100-122. http://dx.doi.org/10.1037/1089-2680.5.2.100

Meissner, C., \& Brigham, J. (2001). Thirty years of investigating the own-race bias in memory for faces-a meta-analytic review. Psychology Public Policy and Law, 7, 3-35. http://dx.doi.org/10.1037/1076-8971.7.1.3 
Miyakoshi, M., Nomura, M., \& Ohira, H. (2007). An ERP study on self-relevant object recognition. Brain and Cognition, 63, 182-189. http://dx.doi.org/10.1016/ j.bandc.2006.12.001

Moran, J. M., Macrae, C. N., Heatherton, T. F., Wyland, C. L., \& Kelly, W. M. (2006) Neuroanatomical evidence for distinct cognitive and affective components of self. Journal of Cognitive Neuroscience, 18, 1586-1594. http://dx.doi.org/10. 1162 /jocn.2006.18.9.1586

Morin, A. (2006). Levels of consciousness and self-awareness: a comparison and integration of various neurocognitive views. Consciousness and Cognition, 15, 358-371. http://dx.doi.org/10.1016/j.concog.2005.09.006

Mu, Y., \& Han, S. (2010). Neural oscillations involved in self-referential processing Neuroimage, 53, 757-768. http://dx.doi.org/10.1016/j.neuroimage.2010.07.008

Oldfield, R. C. (1971). The assessment and analysis of handedness: the Edinburgh. Neuropsychologia, 9, 97-113. http://dx.doi.org/10.1016/0028-3932(71)90067-4

Paller, K. A., Gonsalves, B., Grabowecky, M., Bozic, V. S., \& Yamada, S. (2000). Electrophysiological correlates of recollecting faces of known and unknown individuals. Neuroimage, 11, 98-110. http://dx.doi.org/10.1006/nimg.1999. 0521

Perrin, F., Maquet, P., Peigneux, P., Ruby, P., Degueldre, C., Balteau, E., et al. (2005). Neural mechanisms involved in the detection of our first name: a combined ERPs and PET study. Neuropsychologia, 43, 12-19. http://dx.doi.org/10.1016/j. neuropsychologia.2004.07.0

Perrin, F., Schnakers, C., Schabus, M., Degueldre, C., Goldman, S., Brédart, S., et al. (2006). Brain response to one's own name in vegetative state, minimally conscious state, and locked-in syndrome. Archives of Neurology, 63, 562-569. http://dx.doi.org/10.1001/archneur.63.4.562

Pfütze, E.-M., Sommer, W., \& Schweinberger, S. R. (2002). Age-related slowing in face and name recognition: evidence from event-related brain potentials. Psychology and Aging, 17, 140-160. http://dx.doi.org/10.1037/0882-7974.17.1. 140

Pickering, E. C., \& Schweinberger, S. R. (2003). N200, N250r, and N400 event-related brain potentials reveal three loci of repetition priming for familiar names. Journal of Experimental Psychology: Learning, Memory, and Cognition, 29, 1298-1311. http://dx.doi.org/10.1037/0278-7393.29.6.1298

Polich, J. (2007). Updating P300: an integrative theory of P3a and P3b. Clinical Neurophysiology, 118, 2128-2148. http://dx.doi.org/10.1016/j.clinph.2007.04. 019

Pronin, E., \& Ross, L. (2006). Temporal differences in trait self-ascription: when the self is seen as an other. Journal of Personality and Social Psychology, 90 197-209. http://dx.doi.org/10.1037/0022-3514.90.2.197

Rogers, S. J., \& Pennington, B. F. (1991). A theoretical approach to the deficits in infantile autism. Development and Psychopathology, 3, 137-162. http://dx.doi. org/10.1017/S0954579400000043

Rossion, B., Gauthier, I., Tarr, M. J., Despland, P., Bruyer, R., Linotte, S., et al. (2000). The N170 occipito-temporal component is delayed and enhanced to inverted faces but not to inverted objects: an electrophysiological account of face-specific processes in the human brain. Neuroreport, 11, 69-74. http://dx. doi.org/10.1097/00001756-200001170-00014

Rossion, B., \& Jacques, C. (2008). Does physical interstimulus variance account for early electrophysiological face sensitive responses in the human brain? Ten lessons on the N170. Neuroimage, 39, 1959-1979. http://dx.doi.org/10.1016/j. neuroimage.2007.10.011

Schweinberger, S. R. (1996). How Gorbachev primed Yeltsin: analyses of associative priming in person recognition by means of reaction times and event-related brain potentials. Journal of Experimental Psychology: Learning, Memory, and Cognition, 22, 1383-1407. http://dx.doi.org/10.1037/0278-7393. 22.6.1383

Schweinberger, S. R., Pickering, E. C., Burton, M., \& Kaufmann, J. M. (2002). Human brain potential correlates of repetition priming in face and name recognition. Neuropsychologia, 40, 2057-2073. http://dx.doi.org/10.1016/S00283932(02)00050-7
Schweinberger, S. R., Pickering, E. C., Jentzsch, I., Burton, M., \& Kaufmann, J. M. (2002). Event-related brain potential evidence for a response of inferior temporal cortex to familiar face repetitions. Cognitive Brain Research, 14, 398-409. http://dx.doi.org/10.1016/S0926-6410(02)00142-8

Schweinberger, S. R., Huddy, V., \& Burton, A. M. (2004). N250r: a face-selective brain response to stimulus repetitions. Neuroreport, 15, 1501-1505. http://dx doi.org/10.1097/01.wnr.0000131675.00319.42

Schweinberger, S. R., Ramsay, A. L., \& Kaufmann, J. M. (2006). Hemispheric asymmetries in font-specific and abstractive priming of written personal names: evidence from event-related potentials. Brain Research, 1117, 195-205. http://dx.doi.org/10.1016/j.brainres.2006.08.070

Schweinberger, S. R., Kaufmann, J. M., Moratti, S., Keil, A., \& Burton, A. M. (2007). Brain responses to repetitions of human and animal faces, inverted faces, and objects-an MEG study. Brain Research, 1184, 226-233. http://dx.doi.org/10. 1016/j.brainres.2007.09.079

Scott, L. S., Luciana, M., Wewerka, S., \& Nelson, C. A. (2005). Electrophysiological correlates of facial self-recognition in adults and children. Cognitie, Creier Comportament (Romanian Journal-Translation: Cognition, Brain Behavior), 9, 211-238.

Sedikides, C., \& Gregg, A. P. (2008). Self-enhancement: food for thought. Perspectives on Psychological Science, 3, 102-116. http://dx.doi.org/10.1111/j. 1745-6916.2008.00068.x

Slotter, E. B., \& Gardner, W. L. (2009). Where do you end and I begin? Evidence for anticipatory, motivated self-other integration between relationship partners. Journal of Personality and Social Psychology, 96, 1137-1151. http://dx.doi.org/ 10.1037/a0013882

Sommer, W., Komoss, E., \& Schweinberger, S. R. (1997). Differential localization of brain systems subserving memory for names and faces in normal subjects with event-related potentials. Electroencephalography and Clinical Neurophysiology, 102, 192-199. http://dx.doi.org/10.1016/S0013-4694(96)95577-0

Staffen, W., Kronbichler, M., Aichhorn, M., Mair, A., \& Ladurner, A. M. (2006). Selective brain activity in response to one's own name in the persistent vegetative state. Journal of Neurolology, Neurosurgery \& Psychiatry, 77, 1383-1384. http://dx.doi.org/10.1136/jnnp.2006.095166

Sui, J., Zhu, Y., \& Han, S. (2006). Self-face recognition in attended and unattended conditions: an event related brain potential study. Neuroreport, 17, 423-427. http://dx.doi.org/10.1097/01.wnr.0000203357.65190.61

Tacikowski, P., \& Nowicka, A. (2010). Allocation of attention to self-name and self-face: an ERP study. Biological Psychology, 84, 318-324. http://dx.doi.org/10. 1016/j.biopsycho.2010.03.009

Tacikowski, P., Cygan, H. B., \& Nowicka, A. (2014). Neural correlates of one's own and close-other's name recognition: ERP evidence. Frontiers in Human Neuroscience, 8, 194. http://dx.doi.org/10.3389/fnhum.2014.00194

Tacikowski, P., Jednoróg, K., Marchewka, A., \& Nowicka, A. (2011). How multiple repetitions influence the processing of own, famous and unknown names and faces: An ERP study. International Journal of Psychophysiology, 79, 219-230. http://dx.doi.org/10.1016/j.ijpsycho.2010.10.010

Tanaka, J. W., Curran, T., Porterfield, A. L., \& Collins, D. (2006). Activation of preexisting and acquired face representations: the N250 event-related potential as an index of face familiarity. Journal of Cognitive Neuroscience, 18 , 1488-1497. http://dx.doi.org/10.1162/jocn.2006.18.9.1488

Valentine, T., Moore, V., \& Brédart, S. (1995). Priming production of people's names. Quartely Journal of Experimental Psychology A: Human Experimental Psychology, 48, 513-535. http://dx.doi.org/10.1080/14640749508401404

Wilson, A. E., \& Ross, M. (2003). The identity function of autobiographical memory: time is on our side. Memory, 11,137-149. http://dx.doi.org/10.1080/ 741938210

Zhao, K., Yuan, J., Zhong, Y., Peng, Y., Chen, J., Zhou, L., et al. (2009). Event-related potential correlates of the collective self-relevant effect. Neuroscience Letters 464, 57-61. http://dx.doi.org/10.1016/j.neulet.2009.07.017 